Praxishandbuch Bibliotheksbau 



\section{Praxishandbuch Bibliotheksbau}

Planung - Gestaltung - Betrieb

Herausgegeben von

Petra Hauke und

Klaus Ulrich Werner 
Aus Gründen der besseren Lesbarkeit wird in den Texten in der Regel das generische Maskulinum dann verwendet, wenn kein biologisches Geschlecht gemeint ist (Sexus) oder männliche und weibliche Personen gleichermaßen gemeint sind (Genus, grammatisches Geschlecht). Dies beruht nicht auf einer Diskriminierung des weiblichen Geschlechts. Das Buch richtet sich gleichermaßen an Leserinnen und Leser.

ISBN 978-3-11-040313-8

e-ISBN (PDF) 978-3-11-040318-3

e-ISBN (EPUB) 978-3-11-040323-7

\section{Library of Congress Cataloging-in-Publication Data}

A CIP catalog record for this book has been applied for at the Library of Congress.

\section{Bibliografische Information der Deutschen Nationalbibliothek}

Die Deutsche Nationalbibliothek verzeichnet diese Publikation in der Deutschen Nationalbibliografie; detaillierte bibliografische Daten sind im Internet über http://dnb.dnb.de abrufbar.

(c) 2016 Walter de Gruyter GmbH, Berlin/Boston Umschlagabbildung: Universitätsbibliothek Freiburg, @ K. U. Werner Satz: Dr. Rainer Ostermann, München Druck und Bindung: CPI books GmbH, Leck ๑) Gedruckt auf säurefreiem Papier Printed in Germany

www.degruyter.com 